\author{
RETRACTION
}

\title{
THE WIGNER PROPERTY FOR CL-SPACES AND FINITE-DIMENSIONAL POLYHEDRAL BANACH SPACES - RETRACTION
}

\author{
DONGNI TAN AND XUJIAN HUANG
}

DOI: 10.1017/S0013091521000250, Published by Cambridge University Press on Behalf of The Edinburgh Mathematical Society

The above article [1] has been retracted as it was inadvertently published twice in the journal, Proceedings of the Edinburgh Mathematical Society. The first instance being Tan and Huang, 2021, doi: 10.1017/S0013091521000079 [2] which has already published into issue 64.2. The retracted article is published in this issue for full visibility.

The publishers apologise for this unfortunate duplication and would like to reiterate that this is not the result of any fault or error from the authors.

\section{Reference}

1. D. TAN AND X. HuAng The Wigner property for CL-spaces and finite-dimensional polyhedral Banach spaces. Proceedings of the Edinburgh Mathematical Society (2021) 1-17. doi:10.1017/S0013091521000250

2. D. TAN AND X. HUANG The Wigner property for CL-spaces and finite-dimensional polyhedral Banach spaces. Proceedings of the Edinburgh Mathematical Society 64 (2021) 183-199. doi:10.1017/S0013091521000079

(C) The Author(s), 2021. Published by Cambridge University Press on Behalf of The Edinburgh Mathematical Society. This is an Open Access article, distributed under the terms of the Creative Commons Attribution licence (http://creativecommons.org/ licenses/by/4.0/), which permits unrestricted re-use, distribution, and reproduction in any medium, provided the original work is properly cited. 